\title{
Article \\ KRAS Assessment Following ESMO Recommendations for Colorectal Liver Metastases. Is It Always Worth It?
}

\author{
Olga Morató ${ }^{1, *}$, Maria Villamonte ${ }^{1}(\mathbb{D})$, Patricia Sánchez-Velázquez ${ }^{1}$, Eva Pueyo-Périz ${ }^{1}$, Luís Grande ${ }^{1}$, \\ Benedetto Ielpo ${ }^{1}$, Edoardo Rosso ${ }^{2}$, Alessandro Anselmo ${ }^{3} \mathbb{D}$ and Fernando Burdío ${ }^{1}$
}

1 Department of Surgery, Division of Hepato-Biliary and Pancreatic Surgery, Hospital del Mar, Medical Research Institute (IMIM), University Pompeu Fabra, 08003 Barcelona, Spain; maryvr31@hotmail.com (M.V.) patri_sv5@hotmail.com (P.S.-V.); epueyoperiz@gmail.com (E.P.-P.); LGrande@parcdesalutmar.cat (L.G.); Ielpo.b@gmail.com (B.I.); fburdio@hotmail.com (F.B.)

2 Unité des Maladies de l'Appareil Digestif et Endocrine, Department of Surgery and Robotics, Centre Hospitalier de Luxembourg, L-1210 Luxembourg, Luxembourg; edoardo_rosso@hotmail.com

3 HPB and Transplant Unit, Department of Surgery, Policlinico Tor Vergata, 00173 Rome, Italy; alessandroanselmo.ptv@gmail.com

* Correspondence: olgamoratoredondo@svhg.ie; Tel.: +34-93-2483000

check for

updates

Citation: Morató, O.; Villamonte, M.; Sánchez-Velázquez, P.; Pueyo-Périz, E.; Grande, L.; Ielpo, B.; Rosso, E.; Anselmo, A.; Burdío, F. KRAS Assessment Following ESMO Recommendations for Colorectal Liver Metastases. Is It Always Worth It? Healthcare 2022, 10, 472. https:// doi.org/10.3390/healthcare10030472

Academic Editor: Chrysi Koliaki

Received: 1 February 2022

Accepted: 1 March 2022

Published: 3 March 2022

Publisher's Note: MDPI stays neutral with regard to jurisdictional claims in published maps and institutional affiliations.

Copyright: (C) 2022 by the authors. Licensee MDPI, Basel, Switzerland. This article is an open access article distributed under the terms and conditions of the Creative Commons Attribution (CC BY) license (https:// creativecommons.org/licenses/by/ $4.0 /$ )

\begin{abstract}
Background: Genetic evaluation is essential in assessing colorectal cancer (CRC) and colorectal liver metastasis (CRLM). The aim of this study was to determine the pragmatic value of KRAS on oncological outcomes after CRLM according to the ESMO recommendations and to query whether it is necessary to request KRAS testing in each situation. Methods: A retrospective cohort of 126 patients who underwent surgery for hepatic resection for CRLM between 2009 and 2020 were reviewed. The patients were divided into three categories: wild-type KRAS, mutated $K R A S$ and impractical KRAS according to their oncological variables. The impractical (not tested) $K R A S$ group included patients with metachronous tumours and negative lymph nodes harvested. Disease-free survival (DFS), overall survival (OS) and hepatic recurrence-free survival (HRFS) were calculated by the Kaplan-Meier method, and a multivariable analysis was conducted using the Cox proportional hazards regression model. Results: Of the 108 patients identified, 35 cases had KRAS wild-type, 50 cases had a KRAS mutation and the remaining 23 were classified as impractical KRAS. Significantly longer medians for OS, HRFS and DFS were found in the impractical KRAS group. In the multivariable analyses, the KRAS mutational gene was the only variable that was maintained through OS, HRFS and DFS. For HRFS (HR: 13.63; 95\% confidence interval (CI): $1.35-100.62 ; p=0.010$ for $K R A S$ ), for DFS (HR: 10.06; 95\% CI: 2.40-42.17; $p=0.002$ for $K R A S$ ) and for OS (HR: $4.55 \%$; $95 \% \mathrm{CI}$ : $1.37-15.10 ; p=0.013)$. Conclusion: Our study considers the possibility of unnecessary KRAS testing in patients with metachronous tumours and negative lymph nodes harvested. Combining the genetic mutational profile (i.e., KRAS in specific cases) with tumour characteristics helps patient selection and achieves the best prognosis after CRLM resection.
\end{abstract}

Keywords: KRAS oncogene; colorectal liver metastases; tumour burden score; synchronic tumours

\section{Introduction}

Colorectal cancer (CRC) is the third most common cancer worldwide in terms of incidence $(6.1 \%)$, and second worldwide in terms of mortality $(9.2 \%)[1,2]$. It is estimated that 15-25\% of CRC patients will have developed metastases at the time of primary diagnosis (synchronic tumours), associated with poor prognosis $[3,4]$, while another $25 \%$ of patients will develop metastases in 5 years, half of these will settle into the liver $[5,6]$.

Fast forwarding to today, there has been a remarkable enhancement in overall survival (OS) for colorectal liver metastases (CRLM). Effective targeted chemotherapies, biological agents combined with technically advanced resection plans, have had proven survival benefits [7-12]. Apart from this, tumour morphology and colorectal primary features are 
recognized as independent OS predictors after CRLM resection $[6,13,14]$. The well-known clinicopathological scores by Fong et al. [15] (clinical risk score) and Nordlinger et al. [16] are widely used as OS predictors, while the tumour burden score (TBS) arose as a new robust predictor of long-term survival $[17,18]$.

Novel, more complex biomarkers of tumour biology are also emerging, which, in combination with tumour morphological features, facilitate the prospective assessment of outcomes and follow-up response to treatment after CRLM resection [18,19]. Some studies claim that site-specific patterns of CRC metastases have an impact on patient's outcomes [5] and KRAS mutations play a (key) role in these patterns [20-22]. KRAS mutations affect the risk of recurrence and survival in patients who undergo CRLM resections $[19,21,23]$. They are known to have more aggressive tumour biology than wild-type [22,24,25] and have also been associated with a lower likelihood of having resectable CRLM [26,27]. KRAS and BRAF, the most widely studied oncogene mutations for CRC, should be an indispensable part of tumour analysis [8]. KRAS mutated affects recurrence risk and survival in patients who undergo complete liver resection for CRLM [19-21] by involving them in the surveillance [22].

Although ESMO guidelines for CRLM management recommendations have changed over the last 10 years as the understanding of genetics has developed [28-30], ESMO's and other national societies' [31] recommendations support patients with a CRC metastatic disease KRAS assessment. Nevertheless, it remains controversial whether KRAS testing of CRC is better practiced as a "reflex" or an "on demand" process [26]. The "on demand" process aims to group high-risk features on resected CRCs (those with extramural vascular invasion, nodal metastases and/or a pT4 stage), which is linked to the different biological characteristics synchronous and metachronous liver metastases appear to contain [32].

As such, the objective of the current study was to determine whether KRAS mutational status according to ESMO's CRLM patient-management recommendations in all cases provides a better OS rate, DFS and hepatic recurrence. We sought to better understand oncogene and tumour characteristics allowing us to determine the long-term patient prognosis more accurately.

\section{Methods}

\subsection{Study Design}

From September 2009 to February 2020, all the consecutive patients who underwent curative-intent surgery for CRLM at the HPB unit in the Hospital del Mar's IMIM (Medical Research Institute) were included. Only those who underwent ablation, or a palliative liver resection (R2 resection) were excluded. Figure 1 contains a flowchart of all those included in the retrospective study. The 126 patients were divided into two groups according to our centre's oncological protocol, which started in 2009. The protocol tested KRAS "on demand" only in patients with resected CRCs and high-risk features such as those with a synchronous tumour ( $<6$ months) and/or positive lymph nodes harvested. The impractical (not tested) KRAS group included patients with metachronous tumours ( $>6$ months after CRC diagnoses) and negative lymph nodes harvested. In this group KRAS was not evaluated as it was considered to be unnecessary [33]. According to our protocol, KRAS was only evaluated in 96 patients and the other 30 patients, classified as impractical KRAS, were not evaluated. Based on the ESMO evidence [28] 10 years ago, genomic DNA was isolated from either primary tumour or CRLM tissue specimens and was used as a template for sequencing KRAS codons [30]. Eighteen of these 126 patients were excluded.

Subsequently, 108 patients were finally included in the analysis and divided into 3 categories according to their oncologic biomarker status: KRAS wild-type (absence of the mutation), KRAS mutated and impractical (not tested) KRAS. Of these, 50 patients had $K R A S$ mutated, 35 had KRAS wild-type and the remaining 23 were impractical KRAS (not tested). 


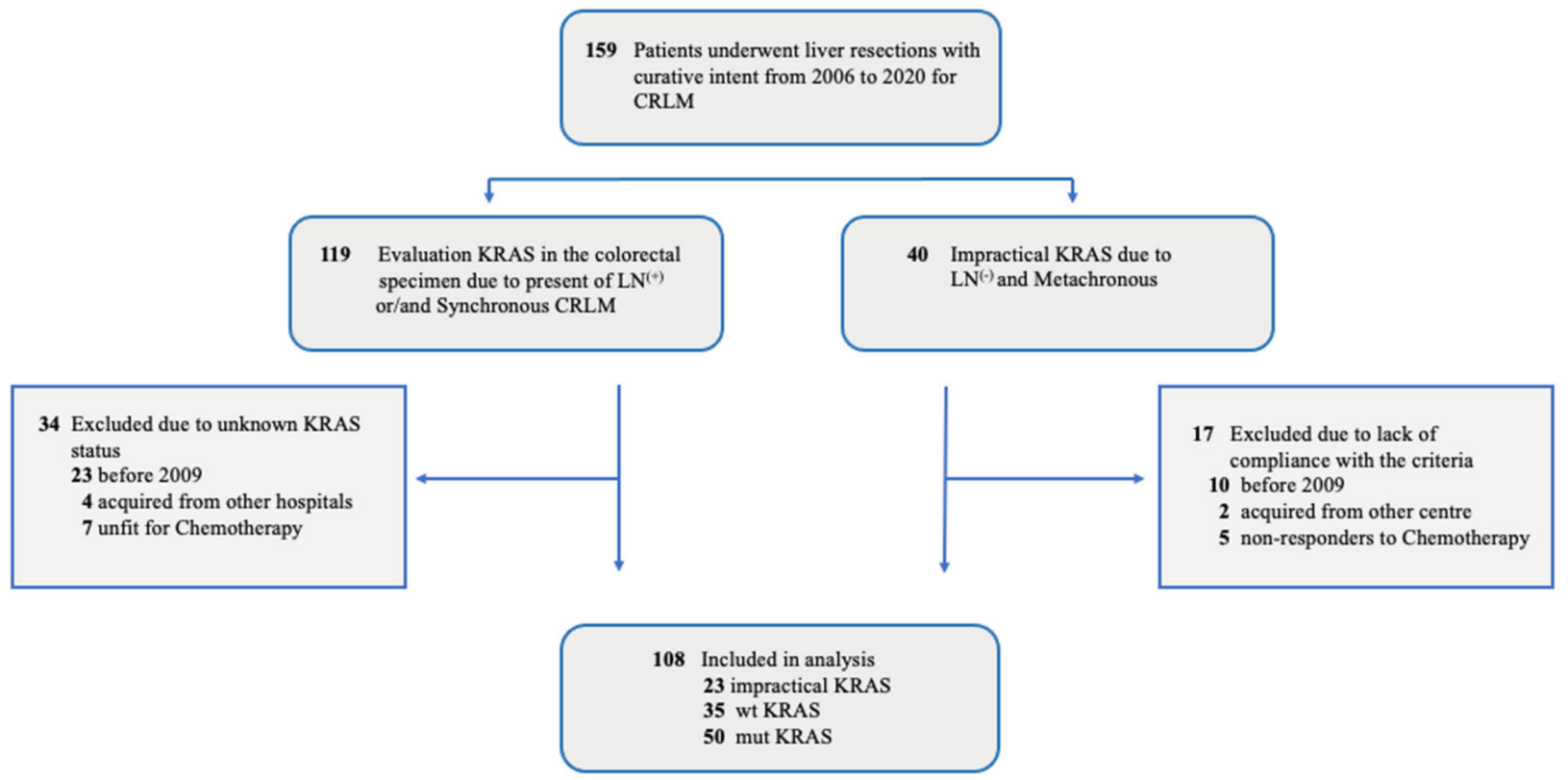

Figure 1. Study Flowchart: CRLM indicates colorectal liver metastases; LN, lymph nodes positive (+) or negative (-); mut $K R A S$, mutated genotype; wt KRAS, wild-type genotype.

The study was conducted in accordance with the principles of the Declaration of Helsinki, the Good Clinical Practice Guidelines and was approved by the hospital's Clinical Research and Ethics Committee approved. All the patients gave their written informed consent prior to surgery and patient data were collected through a prospectively maintained institutional database. This study followed the Strengthening the Reporting of Observational Studies in Epidemiology, Guidelines STROBE.

\subsection{Parameters Studied}

We collected standard demographic, clinicopathologic and genetic variables, including age, sex and characteristics of the extension of the primary CRC including the American Joint Committee on Cancer (AJCC) (T) stage, and the presence or absence of lymph node metastasis $(n)$. The stages were evaluated in each category according to the TNM latest AJCC (8th edition). The characteristics of the resected liver specimen were diameter of largest tumour, number of hepatic tumours using the final histopathological report (including microsatellite lesions) and the TBS. We also collected data on the type of surgery conducted, whether anatomical or atypical, and margins of the pathological specimen, with R1 defined as microscopically positive resection margins [34]. Chemotherapy was evaluated in pre or postoperative terms, cetuximab whether it had been administered, and synchronous ( $<6$ months) vs. metachronous ( $>6$ months) presentation of liver disease.

The primary endpoints of this study were the assessment of OS, disease-free survival (DFS) and hepatic recurrence-free survival (HRFS) in terms of KRAS and TBS. OS was calculated for each patient from the date of surgery to the date of death or last follow-up. Similarly, DFS and HRFS were calculated from the date of resection until the first radiologic or pathologic evidence of recurrence or, in the case of no recurrence, until the date of the last follow-up.

\subsection{Calculation of Tumour Burden Score}

The secondary endpoint was found by evaluating the morphological tumour features through a survival score, TBS. TBS was defined as the distance from the origin on a Cartesian plane that incorporated 2 variables: maximum tumour size ( $x$-axis) and number of liver lesions (y-axis). The Pythagorean theorem was used to calculate the distance of any 
given point from the origin of the plane, whereby $\left(\mathrm{TBS}^{2}=(\text { maximum tumour diameter })^{2}+\right.$ (number of liver lesions) $^{2}$ ) $[17,35]$.

\subsection{Statistical Analysis}

The Kolmogorov-Smirnov test was used to assess the normal distribution of data. Continuous variables were expressed as the median (interquartile range) and compared by the Kruskal-Wallis test. Categorical variables were expressed as absolute numbers and compared using the chi-square test. Survival curves such as HRFS, DFS and OS were estimated using the Kaplan-Meier method, with comparisons of three categories (KRAS mutated, $K R A S$ wild-type and Impractical KRAS-not tested) by the log-rank test. A multivariate landmark analysis was conducted using the Cox proportional hazards regression model to identify independent prognosis predictors in multivariable analysis. Hazard ratios (HR) were reported with 95\% confidence intervals (95\% CI), as appropriate. Factors found to be significant predictors of univariate analysis were subjected to multivariate analysis using the Cox proportional hazards model (backward stepwise regression analysis).

Differences in variables were significant at a threshold of $p<0.05$. The statistical analyses were carried out on SPSS version 25.0 (SPSS, Chicago, IL, USA).

\section{Results}

\subsection{Patient Characteristics}

Baseline characteristics of the 108 patients who underwent hepatic resection did not differ significantly between the patients with $K R A S$ wild-type, KRAS mutated or impractical $K R A S$ (not tested) in terms of age and sex. Regarding CRLM characteristics, impractical $K R A S$ (not tested) was significantly more likely to be less aggressive in the early stages, such as Stages II and III, according to AJCC-UICC. Although the median number of metastatic lesions was similar, the median size of the largest metastatic lesions was significantly smaller in the wild-type KRAS, and TBS was significantly larger in the KRAS mutated group. There was no difference among groups according to R1 margin resections, although KRAS mutated had more patients with postoperative chemotherapy $(p=0.05)$ (Table 1$)$.

Table 1. Clinical Characteristics and Pathologic Features of KRAS-Mutant, KRAS-Wild-Type and Impractical KRAS in Colorectal Cancer Cases.

\begin{tabular}{|c|c|c|c|c|}
\hline Characteristic & $\begin{array}{c}\text { KRAS } \\
\text { Wild-Type } \\
(n=35)\end{array}$ & $\begin{array}{l}\text { KRAS } \\
\text { Mutated } \\
(n=50)\end{array}$ & $\begin{array}{c}\text { Impractical KRAS } \\
\text { (Not Tested) } \\
(n=23)\end{array}$ & $p$-Value \\
\hline \multicolumn{5}{|l|}{ Patient characteristics } \\
\hline Age (year) ${ }^{a}$ & $71(63-76)$ & $69(58-73)$ & $70(66-76)$ & $0.281^{b}$ \\
\hline Female sex & $14(40.0 \%)$ & $16(32.0 \%)$ & $9(39.1 \%)$ & $0.709^{c}$ \\
\hline \multicolumn{5}{|l|}{ Primary tumour characteristics } \\
\hline $\begin{array}{l}\text { T3 or T4 } \\
\text { N1-N2 }\end{array}$ & $30(85.7 \%)$ & $46(92.0 \%)$ & $18(78.3 \%)$ & $0.444^{c}$ \\
\hline CRLM characteristics & $26(74.3 \%)$ & $40(80.0 \%)$ & $0(0 \%)$ & $<0.0001^{\mathrm{c}}$ \\
\hline Stage II or III & $6(17.1 \%)$ & $17(34.0 \%)$ & $18(78.3 \%)$ & $<0.0001^{\mathrm{c}}$ \\
\hline Synchronous CRLM & $29(82.9 \%)$ & $33(66.0 \%)$ & $0(0 \%)$ & $<0.0001^{\mathrm{c}}$ \\
\hline Tumour Burden Score ${ }^{\text {a }}$ & $3.4(2.1-4.9)$ & $4.0(2.9-6.2)$ & $3.5(2.7-5.2)$ & $0.048^{b}$ \\
\hline Tumour number ${ }^{a}$ & $2(1.0-3.0)$ & $2(1.0-3.3)$ & $1(1.0-3.0)$ & $0.159^{b}$ \\
\hline Size of largest tumour size $(\mathrm{cm})^{a}$ & $2(1.5-3.6)$ & $2.8(2.0-5.1)$ & $2.9(2.2-4.2)$ & $0.040^{b}$ \\
\hline \multicolumn{5}{|l|}{ Surgery procedure } \\
\hline Anatomical & $12(34.3 \%)$ & $28(56.0 \%)$ & $9(39.1 \%)$ & \\
\hline Atypical & $23(65.7 \%)$ & $22(44.0 \%)$ & $14(60.9 \%)$ & $0.112^{c}$ \\
\hline $\mathrm{R} 1$ margin resection status & $9(25.7 \%)$ & $19(38.0 \%)$ & $4(17.4 \%)$ & $0.166^{c}$ \\
\hline
\end{tabular}


Table 1. Cont.

\begin{tabular}{|c|c|c|c|c|}
\hline Characteristic & $\begin{array}{c}\text { KRAS } \\
\text { Wild-Type } \\
(n=35)\end{array}$ & $\begin{array}{c}\text { KRAS } \\
\text { Mutated } \\
(n=50)\end{array}$ & $\begin{array}{c}\text { Impractical KRAS } \\
\text { (Not Tested) } \\
(n=23)\end{array}$ & $p$-Value \\
\hline \multicolumn{5}{|l|}{ Chemotherapy } \\
\hline Preoperatively & $9(25.7 \%)$ & $10(20.0 \%)$ & $5(21.7 \%)$ & $0.822^{c}$ \\
\hline Postoperatively & $21(60.0 \%)$ & $33(66.0 \%)$ & $6(26.1 \%)$ & $0.05^{c}$ \\
\hline Cetuximab preoperatively & $0(0 \%)$ & $3(6.0 \%)$ & $0(0 \%)$ & $0.165^{c}$ \\
\hline Cetuximab postoperatively & $1(2.8 \%)$ & $5(10.0 \%)$ & $0(0 \%)$ & $0.182^{c}$ \\
\hline
\end{tabular}

CRLM, colorectal liver metastases. ${ }^{a}$ Continuous variables are expressed as median (interquartile range). Categorical variables are expressed as absolute numbers and percentages. ${ }^{\mathrm{b}}$ Kruskal-Wallis test, ${ }^{\mathrm{c}}$ Chi-square test. Differences in variables were significant at a threshold of $p<0.05$.

\subsection{Cumulative Incidence of Recurrence and Survival According to Different KRAS Expression}

The 5-years DFS rate for patients with the impractical KRAS (not tested), KRAS wildtype and KRAS mutated were $85.9 \%, 33.1 \%$ and $16.3 \%$ respectively $(p<0.0001)$. For HRFS, the 5-year rate was even more striking at that point, in which impractical KRAS (not tested), KRAS wild-type and KRAS mutated were $91.7 \% 62.1 \%$ and $30.1 \%$ respectively $(p=0.001)$. The 5-year OS rates for patients with impractical KRAS (not tested), KRAS wild-type and KRAS mutated were $85.2 \%, 59.5 \%$ and $30.7 \%$ respectively $(p=0.035$ ) (Figure 2 ).
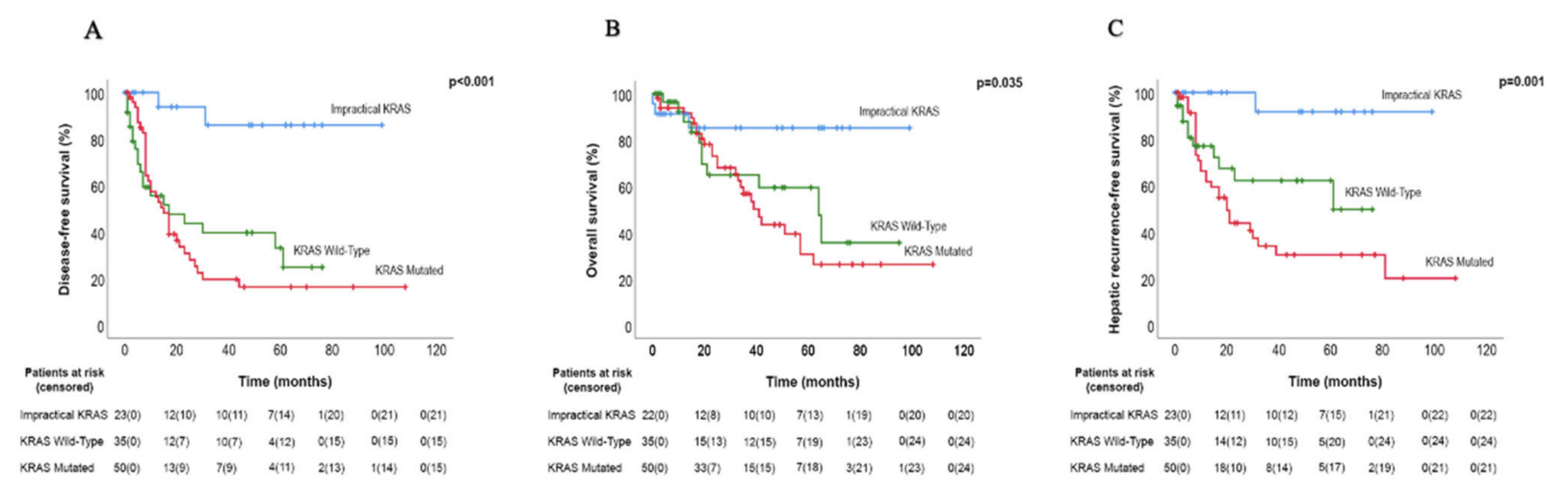

Figure 2. (A) The disease-free survival (DFS) rate is shown for patients with $K R A S$ wild-type versus KRAS mutated versus Impractical KRAS tumours. (B) The overall survival (OS) rate is shown for patients with $K R A S$ wild-type versus KRAS mutated versus Impractical KRAS tumours. (C) The hepatic recurrence rate is shown for patients with $K R A S$ wild-type versus $K R A S$ mutated versus Impractical KRAS tumours. Truncates at 120 months. 95\% CI indicates 95\% confidence interval.

\subsection{Uni-Multivariable Analysis among DFS, HRFS and OS}

Some factors in the univariable analysis were associated with longer DFS (Table 2): age, Stages II or III, synchronous CRLM tumours, TBS, tumour number, KRAS status, R1 margin and preoperative chemotherapy. When we focus on HRFS, the same variables as in the DFS had links with a higher risk of HRFS, except for the largest tumour size, R1 margins and chemotherapy. In the univariable analysis, only three factors were independent predictors of OS, synchronous CRLM tumours, KRAS mutated and postoperative chemotherapy. However, only TBS and KRAS (mutated and wild-type) were maintained in the DFS multivariable analysis as independent factors, the same HRFS independent factors related to the multivariable analysis (Table 3). Nevertheless, when we looked at the multivariable analyses of OS, apart from KRAS mutated remaining as an independent factor, TBS no longer played a key role and was no longer an independent variable, which was instead postoperative chemotherapy (Table 4 ). The KRAS mutational gene was the only variable that survived three times in the multivariable analysis. 
Table 2. Uni-and Multivariable Predictors of Disease-Free Survival in the Entire Cohort.

\begin{tabular}{|c|c|c|c|c|}
\hline \multirow{2}{*}{ Prognostic Factor } & \multicolumn{2}{|c|}{ Univariable Analysis } & \multicolumn{2}{|c|}{ Multivariable Analysis } \\
\hline & HR $(95 \%$ CI) & $p$-Value & HR $(95 \%$ CI) & $p$-Value \\
\hline \multicolumn{5}{|l|}{ Patients' characteristics } \\
\hline Age (year) & $0.98(0.95-0.99)$ & 0.039 & $0.99(0.96-1.02)$ & 0.578 \\
\hline Sex (Male/Female) & $0.97(0.56-1.66)$ & 0.905 & & \\
\hline \multicolumn{5}{|l|}{ Primary tumour characteristics } \\
\hline $\mathrm{T} 1-\mathrm{T} 2 / \mathrm{T} 3-\mathrm{T} 4$ & $1.05(0.26-4.33)$ & 0.942 & & \\
\hline N0/N1-N2 & $2.26(1.23-4.15)$ & 0.008 & $0.93(0.49-1.77)$ & 0.829 \\
\hline Stage II or III & $2.69(1.44-5.01)$ & 0.002 & $1.21(0.61-2.41)$ & 0.581 \\
\hline \multicolumn{5}{|l|}{ CRLM characteristics } \\
\hline Synchronous CRLM & $3.18(1.71-5.93)$ & $<0.001$ & $1.54(0.76-3.11)$ & 0.235 \\
\hline Tumour Burden Score & $1.13(1.06-1.21)$ & $<0.001$ & $1.12(1.04-1.20)$ & 0.001 \\
\hline Tumour number & $1.16(1.08-1.25)$ & $<0.001$ & $1.06(0.94-1.20)$ & 0.370 \\
\hline Size of largest tumour size $(\mathrm{cm})$ & $1.08(0.98-1.18)$ & 0.131 & & \\
\hline \multicolumn{5}{|l|}{ KRAS status } \\
\hline Impractical KRAS (not tested) & 1 & & 1 & \\
\hline KRAS Wild-Type & $9.39(2.19-40.24)$ & 0.003 & $9.57(2.23-41.04)$ & 0.002 \\
\hline KRAS Mutated & $11.17(2.67-46.70)$ & 0.001 & $10.06(2.40-42.17)$ & 0.002 \\
\hline \multicolumn{5}{|l|}{ Surgery procedure } \\
\hline Atypical/Anatomical & $1.16(0.69-1.96)$ & 0.568 & & \\
\hline R1 margin resection status (yes/no) & $1.94(1.13-3.34)$ & 0.017 & $1.52(0.81-2.83)$ & 0.189 \\
\hline \multicolumn{5}{|l|}{ Chemotherapy (yes/no) } \\
\hline Preoperatively & $1.71(1.01-2.89)$ & 0.044 & $0.97(0.56-1.68)$ & 0.909 \\
\hline Postoperatively & $1.05(0.60-1.86)$ & 0.856 & & \\
\hline
\end{tabular}

CRLM, colorectal liver metastases; HR, Hazard ratio; CI, confidence interval. Bold values are statistically significant $(p$-value $<0.05)$.

Table 3. Uni-and Multivariable Predictors of Hepatic Recurrence in the Entire Cohort.

\begin{tabular}{|c|c|c|c|c|}
\hline \multirow{2}{*}{ Prognostic Factor } & \multicolumn{2}{|c|}{ Univariable Analysis } & \multicolumn{2}{|c|}{ Multivariable Analysis } \\
\hline & HR $(95 \%$ CI) & $p$-Value & HR $(95 \%$ CI) & $p$-Value \\
\hline \multicolumn{5}{|l|}{ Patients' characteristic } \\
\hline Age (year) & $0.96(0.94-0.99)$ & 0.011 & & \\
\hline Sex (Male/Female) & $1.01(0.54-1.89)$ & 0.985 & & \\
\hline \multicolumn{5}{|l|}{ Primary tumour characteristics } \\
\hline $\mathrm{T} 1-\mathrm{T} 2 / \mathrm{T} 3-\mathrm{T} 4$ & $0.63(0.15-2.63)$ & 0.528 & & \\
\hline N0/N1-N2 & $2.24(1.10-4.60)$ & 0.027 & $1.08(0.48-2.44)$ & 0.853 \\
\hline Stage II or III & $1.94(0.97-3.89)$ & 0.060 & & \\
\hline \multicolumn{5}{|l|}{ CRLM characteristics } \\
\hline Synchronous CRLM & $2.25(1.12-4.49)$ & 0.022 & $0.93(0.42-2.04)$ & 0.855 \\
\hline Tumour Burden Score & $1.18(1.10-1.27)$ & $<0.0001$ & $1.16(1.08-1.25)$ & $<0.0001$ \\
\hline Tumour number & $1.20(1.10-1.30)$ & $<0.0001$ & $0.95(0.64-1.41)$ & 0.800 \\
\hline Size of largest tumour size $(\mathrm{cm})$ & $1.12(1.01-1.23)$ & 0.027 & $0.87(0.55-1.39)$ & 0.565 \\
\hline \multicolumn{5}{|l|}{ KRAS status } \\
\hline Impractical KRAS (not tested) & 1 & & 1 & \\
\hline KRAS Wild-Type & $9.53(1.23-73.91)$ & 0.031 & $9.44(1.21-73.34)$ & 0.032 \\
\hline KRAS Mutated & $15.77(2.14-116.17)$ & 0.007 & $13.63(1.35-100.62)$ & 0.010 \\
\hline \multicolumn{5}{|l|}{ Surgery procedure } \\
\hline Atypical/ Anatomical & $1.01(0.55-1.87)$ & 0.973 & & \\
\hline R1 margin resection status (yes/no) & $1.67(0.88-3.17)$ & 0.117 & & \\
\hline \multicolumn{5}{|l|}{ Chemotherapy (yes/no) } \\
\hline Preoperatively & $1.60(0.86-2.98)$ & 0.137 & & \\
\hline Postoperatively & $1.56(0.75-3.28)$ & 0.238 & & \\
\hline
\end{tabular}

CRLM, colorectal liver metastases; HR, Hazard ratio; CI, confidence interval. Bold values are statistically significant $(p$-value $<0.05)$. 
Table 4. Uni-and Multivariable Predictors of Overall Survival in the Entire Cohort.

\begin{tabular}{|c|c|c|c|c|}
\hline \multirow{2}{*}{ Prognostic Factor } & \multicolumn{2}{|c|}{ Univariable Analysis } & \multicolumn{2}{|c|}{ Multivariable Analysis } \\
\hline & HR $(95 \%$ CI) & $p$-Value & HR $(95 \%$ CI) & $p$-Value \\
\hline \multicolumn{5}{|l|}{ Patients' characteristic } \\
\hline Age (year) & $1.00(0.97-1.04)$ & 0.805 & & \\
\hline Sex (Male/Female) & $0.49(0.24-0.99)$ & 0.049 & $1.96(0.95-4.04)$ & 0.680 \\
\hline \multicolumn{5}{|l|}{ Primary tumour characteristics } \\
\hline $\mathrm{T} 1-\mathrm{T} 2 / \mathrm{T} 3-\mathrm{T} 4$ & $0.52(0.12-2.18)$ & 0.370 & & \\
\hline N0/N1-N2 & $1.34(0.70-2.57)$ & 0.386 & & \\
\hline Stage II or III & $2.45(1.17-5.16)$ & 0.018 & $0.60(0.26-1.36)$ & 0.217 \\
\hline \multicolumn{5}{|l|}{ CRLM characteristics } \\
\hline Synchronous CRLM & $2.42(1.18-4.97)$ & 0.016 & $1.72(0.75-3.92)$ & 0.200 \\
\hline Tumour Burden Score & $1.05(0.97-1.13)$ & 0.255 & & \\
\hline Tumour number & $1.04(0.95-1.14)$ & 0.404 & & \\
\hline Size of largest tumour size $(\mathrm{cm})$ & $1.05(0.95-1.17)$ & 0.325 & & \\
\hline \multicolumn{5}{|l|}{$K R A S$ status } \\
\hline Impractical KRAS (not tested) & 1 & & 1 & \\
\hline KRAS Wild-Type & $3.15(0.88-11.32)$ & 0.079 & $3.12(0.87-11.19)$ & 0.081 \\
\hline KRAS Mutated & $4.27(1.28-14.17)$ & 0.018 & $4.55(1.37-15.10)$ & 0.013 \\
\hline \multicolumn{5}{|l|}{ Surgery procedure } \\
\hline Atypical/Anatomical & $1.63(0.87-3.08)$ & 0.131 & & \\
\hline $\mathrm{R} 1$ margin resection status (yes/no) & $1.25(0.63-2.46)$ & 0.521 & & \\
\hline \multicolumn{5}{|l|}{ Chemotherapy (yes/no) } \\
\hline Preoperatively & $1.77(0.95-3.31)$ & 0.073 & & \\
\hline Postoperatively & $0.45(0.24-0.85)$ & 0.014 & $0.42(0.224-0.801)$ & 0.008 \\
\hline
\end{tabular}

CRLM, colorectal liver metastases; HR, Hazard ratio; CI, confidence interval. Bold values are statistically significant ( $p$ value $<0.05)$.

\section{Discussion}

The main finding in our analysis appeared as we made further progress in accepting impractical KRAS (patients not tested) as a new entity to be considered as different from KRAS mutated or even KRAS wild-type patients. This interesting finding highlights the idea that testing KRAS as a "reflex" just creates a possibility of unnecessary testing of CRC tissue from patients who never developed metastases [26]. Surprisingly, after analysing and comparing the impractical KRAS (those with metachronous and negative lymph node tumours) with KRAS mutated or KRAS wild-type patients, the difference in terms of HRFS, DFS and OS sharply increased over the others. On the other hand, testing "on demand" means the patients who may benefit from new treatments such as anti-EGFR can be attended. According to the ESMO recommendation for patients with CRLM, anti-EGFR therapies should only be considered for patients with KRAS wild-type. However, it is noteworthy that the ESMO recommendations were being changed in accordance with new times and new genetic knowledge and research.

The exact biological course of the synchronous and metachronous liver metastases is still unknown; however, a review of the literature confirms that they exhibit different biological characteristics to their respective CRC primary tumours [36,37], such as the reduction in p27 expression in the metachronous group, suggesting that there is a "posttranslational" degradation of the proteins in the liver metastases [32], or Kim et al. [32,38] finding a higher expression of VEGF within the synchronous metastases group than in the CRC primary tumour. Others found different immunological response cells in the metachronous group, suggesting a need to clarify whether both groups had to be underlined at the same level. Indeed, it has been accepted that a better understanding of the biological behaviour of tumour biology is a more important factor in survival than surgical margin clearance in the era of modern chemotherapy regimens [39,40].

KRAS is one of the most commonly employed surrogates of genetic alteration in CRC and has been associated with an increased rate of vascular invasion and hematogenous metastasis [20]. KRAS is an oncogene located downstream of the epidermal growth factor 
receptor (EGFR), which is the target for anti-EGFR treatment such as cetuximab. Interestingly, detection of KRAS tumours' mutational status is predictive as a negative marker and the patient is unlikely to benefit from EGFR antibody therapy (cetuximab, bevacizumab and panitumumab), so that patients with $K R A S$ wild-type status seem to respond better to anti-EGFR treatment.

The PRIME study, a randomized control trial, supports a positive benefit-risk profile for panitumumab-FOLFOX4 in patients with previously untreated wild-type KRAS [41]. Nevertheless, another recent RCT between chemotherapy alone or the combination of cetuximab and chemotherapy found that cetuximab seemed to be detrimental to patients with $K R A S$ wild-type in exon 2, with shorter progression-free survival [42]. KRAS genotyping to guide anti-EGFR therapy is evolving rapidly and is being updated. There are some reports of RAS wild-type CRC patients who first show a response to EGFR inhibitors and later demonstrate RAS mutations with progressive disease, suggesting an acquired resistance to these drugs [43]. These findings highlight the imperative need to go deeper into the different genetic evaluations, such as "liquid biopsies", which could play a better role in detecting emerging RAS mutant clones in the near future [26,44]. Unfortunately, our study is retrospective and genotypes could not be determined.

The data strongly suggested that the course of CRLM in the patients depends on both tumour morphology, such as TBS, and the genetic mutational profile [18]. A tumour burden "metro ticket" score based on final pathology has recently been proposed to predict outcomes following CRLM resection [17]. The TBS and KRAS mutation category play a key role in the univariate analysis in providing an increased risk of recurrence. In the multivariable analysis, they are still independent regarding DFS and HRFS; however, they are no longer independently represented in OS. These findings support the fact that both TBS and KRAS are good predictors of survival outcomes after CRLM resection and should be under consideration before surgery is performed.

The current study had several limitations, which ought to be considered when deciphering these results. For instance, given its retrospective design, it could have suffered from selection bias. It should also be noted that KRAS mutational status was resolved either through analysis of the metastasis or of the primary tumour, depending on specimen accessibility. As such, it is possible that the mutational status differed between the two tumour sites.

It should also be noted that this analysis did not take into account potential differences among different KRAS mutation variants because they were not differentiated in the available literature [19]. In addition, other potentially important molecular biomarkers such as BRAF, PI3K and TP53 were not evaluated. Lastly, as the total numbers of patients and impractical KRAS patients included are small, this could introduce another bias factor into the analysis.

\section{Conclusions}

Despite two decades-worth of data, the debate over whether tumour biology should be given more consideration than tumour characteristics among patients with resectable CRLM has not ended. Requesting KRAS makes sense "as a demand" for those patients with more aggressive tumours and should be considered today as an indispensable part of decision making before embarking on aggressive surgical therapy, while in other patients with specific criteria, the KRAS testing could be omitted. Our study emphasizes the importance of considering the assessment of tumour characteristics by the TBS score within a $K R A S$ evaluation in synchronous and aggressive $\mathrm{CRC}$, looking towards a lower recurrence and longer survival.

Author Contributions: Conceptualization, O.M. and F.B.; methodology, F.B.; software, M.V.; validation, L.G., B.I., P.S.-V. and E.P.-P.; formal analysis, F.B.; investigation, O.M.; resources, O.M. and E.P.-P.; data curation, P.S.-V.; writing-original draft preparation, O.M.; writing-review and editing, E.R. and A.A.; visualization, B.I.; supervision, L.G., F.B., P.S.-V., M.V. All authors have read and agreed to the published version of the manuscript. 
Funding: This research received no external funding.

Institutional Review Board Statement: The study was conducted in accordance with the Declaration of Helsinki and was approved by the hospital's Clinical Research and Ethics Committee.

Informed Consent Statement: Informed consent was obtained from all subjects involved in the study.

Data Availability Statement: Not applicable.

Conflicts of Interest: The authors declare no conflict of interest.

\section{References}

1. Bray, F.; Ferlay, J.; Soerjomataram, I.; Siegel, R.L.; Torre, L.A.; Jemal, A. Global cancer statistics 2018: GLOBOCAN estimates of incidence and mortality worldwide for 36 cancers in 185 countries. CA Cancer J. Clin. 2018, 68, 394-424. [CrossRef]

2. Siegel, R.L.; Miller, K.D.; Fedewa, S.A.; Ahnen, D.J.; Meester, R.G.S.; Barzi, A.; Jemal, A. Colorectal cancer statistics, 2017. CA Cancer J. Clin. 2017, 67, 177-193. [CrossRef] [PubMed]

3. van der Geest, L.G.M.; Lam-Boer, J.; Koopman, M.; Verhoef, C.; Elferink, M.A.G.; de Wilt, J.H.W. Nationwide trends in incidence, treatment and survival of colorectal cancer patients with synchronous metastases. Clin. Exp. Metastasis 2015, 32, 457-465. [CrossRef]

4. Viganò, L.; Capussotti, L.; Lapointe, R.; Barroso, E.; Hubert, C.; Giuliante, F.; Ijzermans, J.N.M.; Mirza, D.F.; Elias, D.; Adam, R. Early recurrence after liver resection for colorectal metastases: Risk factors, prognosis, and treatment. A LiverMetSurvey-based study of 6,025 patients. Ann. Surg. Oncol. 2014, 21, 1276-1286. [CrossRef]

5. van Gestel, Y.R.; de Hingh, I.H.; van Herk-Sukel, M.P.; van Erning, F.N.; Beerepoot, L.V.; Wijsman, J.H.; Slooter, G.D.; Rutten, H.J.; Creemers, G.J.M.; Lemmens, V.E. Patterns of metachronous metastases after curative treatment of colorectal cancer. Cancer Epidemiol. 2014, 38, 448-454. [CrossRef]

6. Kow, A.W.C. Hepatic metastasis from colorectal cancer. J. Gastrointest. Oncol. 2019, 10, 1274-1298. [CrossRef] [PubMed]

7. Kopetz, S.; Chang, G.J.; Overman, M.J.; Eng, C.; Sargent, D.; Larson, D.W.; Grothey, A.; Vauthey, J.-N.; Nagorney, D.M.; McWilliams, R.R. Improved survival in metastatic colorectal cancer is associated with adoption of hepatic resection and improved chemotherapy. J. Clin. Oncol. 2009, 27, 3677-3683. [CrossRef] [PubMed]

8. Chakedis, J.; Schmidt, C.R. Surgical Treatment of Metastatic Colorectal Cancer. Surg. Oncol. Clin. North Am. 2018, 27, 377-399. [CrossRef]

9. Wu, Y.; Liu, F.; Cai, G.; Wang, M.; Zheng, H.; Wang, L.; Li, X.; Cai, S.; Xu, Y. Surgical management of colorectal cancer: The Fudan University Shanghai Cancer Center experience. Transl. Cancer Res. 2017, 6, 1351-1357. [CrossRef]

10. Fakih, M.G. Metastatic colorectal cancer: Current state and future directions. J. Clin. Oncol. 2015, 33, 1809-1824. [CrossRef]

11. Theodore, N.; Arnold, P.M.; Mehta, A.I. Introduction: The rise of the robots in spinal surgery. Neurosurg. Focus 2018, 45, 1-2. [CrossRef] [PubMed]

12. D'Angelica, M.I.; Correa-Gallego, C.; Paty, P.B.; Cercek, A.; Gewirtz, A.N.; Chou, J.F.; Capanu, M.; Kingham, T.P.; Fong, Y.; DeMatteo, R.P.; et al. Phase ii trial of hepatic artery infusional and systemic chemotherapy for patients with unresectable hepatic metastases from colorectal cancer conversion to resection and long-term outcomes. Ann. Surg. 2015, 261, 353-360. [CrossRef]

13. Pawlik, T.M.; Scoggins, C.R.; Zorzi, D.; Abdalla, E.K.; Andres, A.; Eng, C.; Curley, S.A.; Loyer, E.M.; Muratore, A.; Mentha, G.; et al. Effect of surgical margin status on survival and site of recurrence after hepatic resection for colorectal metastases. Ann. Surg. 2005, 241, 715-724. [CrossRef] [PubMed]

14. Hamady, Z.Z.R.; Cameron, I.C.; Wyatt, J.; Prasad, R.K.; Toogood, G.J.; Lodge, J.P.A. Resection margin in patients undergoing hepatectomy for colorectal liver metastasis: A critical appraisal of the $1 \mathrm{~cm}$ rule. Eur. J. Surg. Oncol. 2006, 32, 557-563. [CrossRef] [PubMed]

15. Fong, Y.; Fortner, J.; Sun, R.L.; Brennan, M.F.; Blumgart, L.H. Clinical Score for Predicting Recurrence After Hepatic Resection for Metastatic Colorectal Cancer. Ann. Surg. 1999, 230, 309. [CrossRef] [PubMed]

16. Nordlinger, B.; Guiguet, M.; Vaillant, J.; Balladur, P.; Boudjema, K.; Bachellier, P.; Jaeck, D. Surgical resection of colorectal carcinoma metastases to the liver: A prognostic scoring system to improve case selection, based on 1568 patients. Cancer 1996, 77 , 1254-1262. [CrossRef]

17. Sasaki, K.; Morioka, D.; Conci, S.; Margonis, G.A.; Sawada, Y.; Ruzzenente, A.; Kumamoto, T.; Iacono, C.; Andreatos, N.; Guglielmi, A.; et al. The Tumor Burden Score: A New 'metro-ticket' Prognostic Tool for Colorectal Liver Metastases Based on Tumor Size and Number of Tumors. Ann. Surg. 2018, 267, 132-141. [CrossRef]

18. Tsilimigras, D.I.; Hyer, J.M.; Bagante, F.; Guglielmi, A.; Ruzzenente, A.; Alexandrescu, S.; Poultsides, G.; Sasaki, K.; Aucejo, F.; Pawlik, T.M. Resection of Colorectal Liver Metastasis: Prognostic Impact of Tumor Burden vs. KRAS Mutational Status. J. Am. Coll Surg. 2020, 232, 590-598. [CrossRef]

19. Tosi, F.; Magni, E.; Amatu, A.; Mauri, G.; Bencardino, K.; Truini, M.; Veronese, S.; De Carlis, L.; Ferrari, G.; Nichelatti, M.; et al. Effect of KRAS and BRAF Mutations on Survival of Metastatic Colorectal Cancer After Liver Resection: A Systematic Review and Meta-Analysis. Clin. Colorectal Cancer 2017, 16, e153-e163. [CrossRef] 
20. Yaeger, R.; Cowell, E.; Chou, J.F.; Gewirtz, A.N.; Borsu, L.; Vakiani, E.; Solit, D.B.; Rosen, N.; Capanu, M.; Ladanyi, M.; et al. RAS Mutations Affect Pattern of Metastatic Spread and Increase Propensity for Brain Metastasis in Colorectal Cancer. Cancer 2015, 121, 1195-1203. [CrossRef]

21. Kemeny, N.E.; Chou, J.F.; Capanu, M.; Gewirtz, A.N.; Cercek, A.; Kingham, T.P.; Jarnagin, W.R.; Fong, Y.C.; DeMatteo, R.P.; Allen, P.J.; et al. KRAS mutation influences recurrence patterns in patients undergoing hepatic resection of colorectal metastases. Cancer 2014, 120, 3965-3971. [CrossRef]

22. Vauthey, J.-N.; Zimmitti, G.; Kopetz, S.E.; Shindoh, J.; Chen, S.S.; Andreou, A.; Curley, S.A.; Aloia, T.A.; Maru, D.M. RAS mutation status predicts survival and patterns of recurrence in patients undergoing hepatectomy for colorectal liver metastases. Ann. Surg. 2014, 258, 619-626. [CrossRef] [PubMed]

23. Hatta, A.A.Z.; Pathanki, A.M.; Hodson, J.; Sutcliffe, R.P.; Marudanayagam, R.; Roberts, K.J.; Chatzizacharias, N.; Isaac, J.; Muiesan, P.; Taniere, P.; et al. The effects of resection margin and KRAS status on outcomes after resection of colorectal liver metastases. HPB 2020, 23, 90-98. [CrossRef]

24. Margonis, G.A.; Buettner, S.; Andreatos, N.; Sasaki, K.; Ijzermans, J.N.; van Vugt, J.L.; Pawlik, T.M.; Choti, M.A.; Cameron, J.L.; $\mathrm{He}$, J.; et al. Anatomical Resections Improve Disease-free Survival in Patients with KRAS -mutated Colorectal Liver Metastases. Ann. Surg. 2017, 266, 641-649. [CrossRef]

25. Margonis, G.A.; Buettner, S.; Andreatos, N.; Kim, Y.; Wagner, D.; Sasaki, K.; Beer, A.; Schwarz, C.; Løes, I.M.; Smolle, M.; et al. Association of BRAF mutations with survival and recurrence in surgically treated patients with metastatic colorectal liver cancer. JAMA Surg. 2018, 153, e180996. [CrossRef] [PubMed]

26. Wong, N.A.C.S.; Gonzalez, D.; Salto-Tellez, M.; Butler, R.; Diaz-Cano, S.J.; Ilyas, M.; Newman, W.; Shaw, E.; Taniere, P.; Walsh, S.V. RAS testing of colorectal carcinoma-A guidance document from the Association of Clinical Pathologists Molecular Pathology and Diagnostics Group. J. Clin. Pathol. 2014, 67, 751-757. [CrossRef]

27. Yaeger, R.; Cowell, E.; Joanne, F.; Chou, J.F.; Alexandra, N.; Laetitia, B.; Efsevia, V.; Sylvester, B.E.; Kemeny, N.E.; Hechtman, J.F.; et al. RAS mutations Affect Pattern of Metastatic Spread and Increase Propensity for Brain Metastasis in Colorectal Cancer. Cancer Res. 2015, 47, 549-562. [CrossRef] [PubMed]

28. van Cutsem, E.; Nordlinger, B.; Cervantes, A. Advanced colorectal cancer: ESMO clinical practice guidelines for treatment. Ann. Oncol. 2010, 21 (Suppl. S5), v93-v97. [CrossRef]

29. Schmoll, H.J.; Van Cutsem, E.; Stein, A.; Valentini, V.; Glimelius, B.; Haustermans, K.; Nordlinger, B.; van de Velde, C.J.; Balmaña, J.; Regula, J.; et al. Esmo consensus guidelines for management of patients with colon and rectal cancer. A personalized approach to clinical decision making. Ann. Oncol. 2012, 23, 2479-2516. [CrossRef]

30. Van Cutsem, E.; Cervantes, A.; Adam, R.; Sobrero, A.; Van Krieken, J.H.; Aderka, D.; Aguilar, E.A.; Bardelli, A.; Benson, A.; Bodoky, G.; et al. ESMO consensus guidelines for the management of patients with metastatic colorectal cancer. Ann. Oncol. 2016, 27, 1386-1422. [CrossRef]

31. García-Alfonso, P.; García-Foncillas, J.; Salazar, R.; Pérez-Segura, P.; Garcia-Carbonero, R.; Musulén-Palet, E.; Cuatrecasas, M.; Landolfi, S.; Cajal, S.R.Y.; Navarro, S. Updated guidelines for biomarker testing in colorectal carcinoma: A national consensus of the Spanish Society of Pathology and the Spanish Society of Medical Oncology. Clin. Transl. Oncol. 2015, 17, 264-273. [CrossRef] [PubMed]

32. Slesser, A.A.P.; Georgiou, P.; Brown, G.; Mudan, S.; Goldin, R.; Tekkis, P. The tumour biology of synchronous and metachronous colorectal liver metastases: A systematic review. Clin. Exp. Metastasis 2013, 30, 457-470. [CrossRef] [PubMed]

33. Dienstmann, R.; Mason, M.J.; Sinicrope, F.A.; Phipps, A.I.; Tejpar, S.; Nesbakken, A.; Danielsen, S.A.; Sveen, A.; Buchanan, D.D.; Clendenning, M.; et al. Prediction of overall survival in stage II and III colon cancer beyond TNM system: A retrospective, pooled biomarker study. Ann. Oncol. Off. J. Eur Soc. Med. Oncol. 2017, 28, 1023-1031. [CrossRef]

34. Adam, R.; de Gramont, A.; Figueras, J.; Kokudo, N.; Kunstlinger, F.; Loyer, E.; Poston, G.; Rougier, P.; Rubbia-Brandt, L.; Sobrero, A.; et al. Managing synchronous liver metastases from colorectal cancer: A multidisciplinary international consensus. Cancer Treat. Rev. 2015, 41, 729-741. [CrossRef] [PubMed]

35. Sasaki, K.; Margonis, G.A.; Andreatos, N.; Zhang, X.-F.; Buettner, S.; Wang, J.; Deshwar, A.; He, J.; Wolfgang, C.L.; Weiss, M.; et al. The prognostic utility of the "Tumor Burden Score" based on preoperative radiographic features of colorectal liver metastases. $J$. Surg. Oncol. 2017, 116, 515-523. [CrossRef] [PubMed]

36. van der Wal, G.E.; Gouw, A.S.; Kamps, J.A.; Moorlag, H.E.; Bulthuis, M.L.; Molema, G.; de Jong, K.P. Angiogenesis in synchronous and metachronous colorectal liver metastases: The liver as a permissive soil. Ann. Surg. 2012, 255, 86-94. [CrossRef] [PubMed]

37. Miyagawa, S.; Soeda, J.; Takagi, S.; Miwa, S.; Ichikawa, E.; Noike, T. Prognostic significance of mature dendritic cells and factors associated with their accumulation in metastatic liver tumors from colorectal cancer. Hum. Pathol. 2004, 35, 1392-1396. [CrossRef]

38. Kim, J.; Takeuchi, H.; Lam, S.T.; Turner, R.R.; Wang, H.-J.; Kuo, C.; Foshag, L.; Bilchik, A.J.; Hoon, D.S. Chemokine receptor CXCR4 expression in colorectal cancer patients increases the risk for recurrence and for poor survival. J. Clin. Oncol. 2005, 23, 2744-2753. [CrossRef]

39. Margonis, G.A.; Sergentanis, T.N.; Ntanasis-Stathopoulos, I.; Andreatos, N.; Tzanninis, I.G.; Sasaki, K.; Psaltopoulou, T.; Wang, J.; Buettner, S.; He, J.; et al. Impact of Surgical Margin Width on Recurrence and Overall Survival Following R0 Hepatic Resection of Colorectal Metastases: A Systematic Review and Meta-analysis. Ann. Surg. 2018, 267, 1047-1055. [CrossRef] 
40. Truant, S.; Séquier, C.; Leteurtre, E.; Boleslawski, E.; Elamrani, M.; Huet, G.; Duhamel, A.; Hebbar, M.; Pruvot, F. Tumour biology of colorectal liver metastasis is a more important factor in survival than surgical margin clearance in the era of modern chemotherapy regimens. HPB 2015, 17, 176-184. [CrossRef]

41. Douillard, J.Y.; Siena, S.; Cassidy, J.; Tabernero, J.; Burkes, R.; Barugel, M.; Humblet, Y.; Bodoky, G.; Cunningham, D.; Jassem, J.; et al. Final results from PRIME: Randomized phase III study of panitumumab with FOLFOX4 for first-line treatment of metastatic colorectal cancer. Ann. Oncol. 2014, 25, 1346-1355. [CrossRef] [PubMed]

42. Primrose, J.; Falk, S.; Finch-Jones, M.; Valle, J.; O’Reilly, D.; Siriwardena, A.; Hornbuckle, J.; Peterson, M.; Rees, M.; Iveson, T.; et al. Systemic chemotherapy with or without cetuximab in patients with resectable colorectal liver metastasis: The New EPOC randomised controlled trial. Lancet Oncol. 2014, 15, 601-611. [CrossRef]

43. Diaz, L.A.; Williams, R.T.; Wu, J.; Kinde, I.; Hecht, J.R.; Berlin, J.; Allen, B.; Bozic, I.; Reiter, J.G.; Nowak, M.A.; et al. The molecular evolution of acquired resistance to targeted EGFR blockade in colorectal cancers. Nature 2012, 486, 537-540. [CrossRef]

44. Nash, G.M.; Gimbel, M.; Shia, J.; Nathanson, D.R.; Ndubuisi, M.I.; Zeng, Z.S.; Kemeny, N.; Paty, P.B. KRAS Mutation Correlates with Accelerated Metastatic Progression in Patients with Colorectal Liver Metastases. Ann. Surg. Oncol. 2010, 17, 572-578. [CrossRef] [PubMed] 